\title{
Early cholecystectomy for acute cholecystitis: a population- based retrospective cohort study of variation in practice
}

\author{
Charles de Mestral MD, Andreas Laupacis MD MSc, Ori D. Rotstein MD MSc, Jeffrey S. Hoch PhD, \\ Barbara Haas MD PhD, David Gomez MD PhD, Brandon Zagorski MS, Avery B. Nathens MD PhD
}

\section{Abstract}

Background: Despite evidence in favour of early cholecystectomy for most patients with acute cholecystitis, variation in practice has been reported across hospitals worldwide. We sought to characterize the extent and potential sources of variation in the performance of early cholecystectomy for acute cholecystitis within a large regional health care system.

\begin{abstract}
Methods: We used a population-based retrospective cohort design. The cohort was limited to adults with a first episode of acute cholecystitis, admitted through the emergency department. Patients were identified using administrative databases comprising all emergency department visits and hospital admissions in Ontario from 2004 to 2010. Patient and hospital characteristics associated with early cholecystectomy (within $7 \mathrm{~d}$ of emergency department presentation) were identified using multilevel logistic regression.
\end{abstract}

Results: We identified 24437 patients admitted to 106 hospitals with a first episode of acute cholecystitis. Most (58\%, $n=14286)$ underwent early cholecystectomy. Rates of early cholecystectomy varied widely across hospitals (median $51 \%$, interquartile range [IQR] 25\%-72\%), even among healthy patients aged 18-49 years with uncomplicated cholecystitis (median 74\%, IQR 41\%-88\%). Multivariable multilevel analysis showed that hospitals in the lowest quartile for volume of acute cholecystitis admissions had the lowest adjusted odds of early cholecystectomy (odds ratio $0.53,95 \%$ confidence interval $0.35-0.78$ ) and that hospital effects accounted for half $(27 \%)$ of the explained variation (53\%) in early cholecystectomy.

Interpretation: Across the hospitals of a regional health care system, similar patients with acute cholecystitis did not receive comparable care. Hospital-specific initiatives should be considered to facilitate early cholecystectomy for patients with acute cholecystitis.

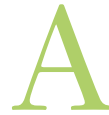
cute cholecystitis is a ubiquitous cause of admission to hospital for gastrointestinal disease and is definitively managed with cholecystectomy.,2 Randomized controlled trials, meta-analyses and expert consensus support early laparoscopic cholecystectomy on first hospital admission for most patients with acute cholecystitis without severe sepsis. ${ }^{3-12}$ Compared with delaying cholecystectomy until after discharge, early laparoscopic cholecystectomy within 7 days of symptom onset is associated with a shorter total length of hospital stay and a similar risk of conversion to open cholecystectomy. ${ }^{3,8-12}$ Further support for early intervention can be drawn from reports showing a $20 \%$ risk of recurrent gallstone-related symptoms if cholecystectomy is delayed..$^{10-13}$

In spite of the evidence favouring early intervention, inconsistency in delivering what many consider best practice has been reported worldwide. Reports out of the United Kingdom, Japan and the United States show rates of early cholecystectomy ranging from $36 \%$ to $88 \% .{ }^{14-18}$ However, because of differences in the setting and cohort characteristics across published studies, our understanding of the extent and underlying etiology of the inconsistent application of early cholecystectomy remains circumstantial. We postulated that a better understanding of the factors associated with the perfor- mance of early cholecystectomy would provide opportunities to address the gap between evidence and practice. Our objective was, therefore, to evaluate the extent of variation across hospitals in a large regional health care system and to identify patient and hospital characteristics associated with early cholecystectomy.

\section{Methods}

\section{Study design and setting}

We performed a population-based retrospective cohort study involving all adults with a first episode of acute cholecystitis emergently admitted to an acute care hospital between Apr. 1, 2004, and Mar. 31, 2010, in Ontario. We

Competing interests: None declared.

This article has been peer reviewed.

Correspondence to: Charles de Mestral, charles.demestral@mail.utoronto.ca

CMAJ Open 2013.DOI:10.9778/cmajo.20130001 
compared rates of early cholecystectomy across hospitals, and we used multivariable multilevel logistic regression to identify patient and hospital characteristics associated with performing early cholecystectomy.

Ontario is Canada's most populous province, with over 13 million residents. All medically necessary hospital and physician services for Ontario residents are paid for by the provincial Ministry of Health, and there are no private general hospitals.

This study was approved by the Research Ethics Board of Sunnybrook Health Sciences Centre.

\section{Data sources}

We identified patients from the Canadian Institute for Health Information's Discharge Abstract Database, which contains demographic, diagnostic and procedural information for all hospital admissions in Ontario. Admission via the emergency department was confirmed through linkage to the National Ambulatory Care Reporting System database, which captures all emergency department visits. To derive certain covariates (patient comorbidities and hospital after-hours procedure volume), we supplemented the Discharge Abstract Database with data from the Ontario Health Insurance Plan billing database, which contains all physician claims. These datasets were deterministically linked through a unique encrypted patient identifier and have been validated for a variety of exposures and comorbidities. ${ }^{19-23}$ In a multicentre validation study, almost perfect agreement was found between Ontario's Discharge Abstract Database and reabstracted data for cholecystectomy coding and coding of gallstone disease as the most responsible diagnosis. ${ }^{19}$

\section{Study cohort}

The cohort included residents of Ontario aged 18 years and older who were admitted to hospital via the emergency department with a most responsible diagnosis of acute cholecystitis (International Statistical Classification of Diseases and Related Health Problems, enhanced Canadian version of the 10th revision [ICD-10-CA] codes K80.0, K80.1, K80.4, K81.0, K81.8, K81.9). We restricted our analysis to patients with a first episode of acute cholecystitis and without prior gallstonerelated admissions or emergency department visits in the 2 years preceding their index admission. We also excluded patients directly admitted to an intensive care unit. We considered admission to an intensive care unit to be a surrogate for cholecystitis with severe sepsis, consistent with the Tokyo consensus definition of severe cholecystitis. ${ }^{24}$ We also excluded patients who underwent cholecystostomy tube placement because this may suggest either severe cholecystitis, acalculous cholecystitis or substantial comorbidity that might preclude operative intervention at any time. Less than $0.5 \%$ of patients were excluded because of missing covariate information.

There were 2 exclusions at the hospital level. First, we excluded hospitals where there was no general surgeon, because patients presenting to these hospitals could not have had an early cholecystectomy. Because data on the availability of physicians at specific hospitals were not directly available, we excluded hospitals where no appendectomy was recorded over the 6-year study period. Appendectomy was chosen as a surrogate for surgeon availability because appendicitis is common and is managed in most cases with urgent appendectomy if surgical expertise is available. Finally, to provide more robust estimates of rates, we excluded hospitals with fewer than 5 patients who met the entry criteria per study year. These 2 criteria resulted in the exclusion of 52 of 158 hospitals.

\section{Outcome measure}

The primary outcome of interest was early cholecystectomy, defined as cholecystectomy within 7 days of presentation to an emergency department.

\section{Covariates}

Several patient and hospital characteristics were considered as potential explanatory variables influencing the performance of early cholecystectomy. Patient characteristics included age, sex, income level, comorbidity level, concomitant common bile duct obstruction and pancreatitis. We used income quintile as a crude surrogate for socioeconomic status; income quintile was derived from the median household income of the patient's postal code of residence based on 2001 and 2006 census data. ${ }^{25}$ Comorbidity level was captured using the Johns Hopkins Aggregated Diagnosis Group scoring system. ${ }^{26}$ Using inpatient and outpatient records in the 2 years preceding the index admission, we calculated an Aggregate Diagnosis Group-based comorbidity index according to an algorithm validated for the prediction of 1-year mortality in a large cohort of adult Ontarians. $^{27}$

We considered hospital characteristics including teaching status (academic teaching v. nonteaching) as recognized by the Ontario Ministry of Health, ${ }^{28}$ annual volume of acute cholecystitis admissions (quartiles) and annual volume of elective cholecystectomies (quartiles). We also considered the possibility that a hospital's policy regarding the use of operating room resources after hours (i.e., evenings, nights, weekends) or operating room availability might influence the likelihood of early cholecystectomy. Therefore, as a standardized measure of operating room use after hours, we derived a variable corresponding to the ratio of total after-hours operative cases (for all surgical specialties) divided by the number of all-cause emergency department visits. Lower values are indicative of lower after-hours use of operating rooms.

\section{Statistical analysis}

We first calculated the crude rate of early cholecystectomy at each hospital for all patients. To better understand the source of variation, we also explored rates across hospitals for young healthy patients ( $<50 \mathrm{yr}$ old in lowest comorbidity quartile) with uncomplicated disease (without common bile duct obstruction or pancreatitis). Variation across hospitals is presented using funnel plots in which each hospital's early cholecystectomy rate is plotted against their volume of acute cholecystitis admissions. The funnel plots graphically show whether the variation in the rate of early cholecystectomy across hospitals is in excess or within the range expected based on chance alone. Ninety-nine percent control limits frame the range of 
random variation around the overall cholecystectomy rate and are defined as exact binomial confidence intervals that vary as a function of the volume of acute cholecystitis admissions. ${ }^{29} \mathrm{~A}$ hospital outside the control limits is therefore interpreted as having an early cholecystectomy rate outside the range of random variation that would be expected based on chance alone.

We then evaluated the association of patient and hospital characteristics with early cholecystectomy using multilevel (2-level) logistic regression, which accounts for the non-independence of patients admitted to the same hospital. ${ }^{30}$ Model calibration was examined through observed versus predicted outcome plots, and discrimination was quantified with the c-statistic.

To evaluate the relative importance of hospital characteristics and patient case-mix, we compared the proportion of explained outcome variation in the multilevel logistic model with patient and hospital characteristics to a standard logistic model containing only the patient covariates. Each model's respective proportion of explained outcome variation was calculated as the squared Pearson correlation coefficient between the probabilities of early cholecystectomy predicted by the model and the observed outcomes. ${ }^{31}$

In addition, we used the multilevel model to quantify the extent of variation between hospitals, adjusted for differences in patient case-mix, by calculating the median odds ratio (OR). ${ }^{32}$ The median OR is the median value of all possible ratios of the odds of cholecystectomy in 2 patients with the same covariates admitted to 2 randomly selected distinct hospitals. By convention, the odds of the patient at the hospital with the highest propensity for cholecystectomy are used as the numerator of the ratio, such that the median OR is always greater than or equal to 1 . As an example, a median OR of 3.0 suggests a 3 -fold median difference in the odds of early cholecystectomy for 2 similar patients admitted to distinct randomly selected hospitals. The median OR can also be directly compared with the fixed effects in the study (e.g., patient age, sex), thereby informing a meaningful interpretation of its magnitude.

All analyses were performed using SAS 9.2. Given the large sample size, we considered a 2 -tailed $\alpha$ less than 0.01 to be statistically significant.

\section{Results}

\section{Study cohort}

We identified 24437 patients, admitted to 106 hospitals, with a first episode of acute cholecystitis who met our inclusion criteria (Figure 1). The median number of patients per hospital was 196 (interquartile range [IQR] 71-357). Teaching hospitals comprised $13 \%$ of hospitals and cared for $21 \%$ of patients. The cohort was evenly distributed across study years. Over half of the included patients were female (59\%), and the mean age was 56 ( \pm standard deviation 18 ) years. Concurrent common bile duct obstruction and pancreatitis were present in $11 \%$ and $5 \%$ of patients, respectively. Overall, $14286(58 \%)$ patients underwent early cholecystectomy (Appendix 1, www.cmajopen .ca/content/1/2/E62/suppl/DC1).

\section{Early cholecystectomy rates across hospitals}

There was marked variation in the rate of early cholecystectomy across hospitals (median 51\%, IQR 25\%-72\%). This variation remained evident even when the analysis was limited to young healthy patients $(<50 \mathrm{yr}$ and in the lowest comorbidity quartile) with uncomplicated disease (without common bile duct obstruction or pancreatitis) (median 74\%, IQR $41 \%-88 \%)$. In both the full cohort and in the younger healthy subgroup, the variation in early cholecystectomy was in excess of that expected by chance alone, as shown by the large number of hospitals lying outside the $99 \%$ control limits shown in the funnel plots (Figures 2A and B). In other words, the funnel plots suggest that factors other than chance explain the extent of variation. As we expected, there was less variation within the more homogeneous younger subgroup, as shown by a smaller proportion of hospitals lying outside the control limits (Figure 2B).

\section{Effect of covariates on variation}

On multivariable multilevel analysis, patients who were younger, female, with a lower comorbidity burden and without common bile duct obstruction were more likely to undergo early operative intervention (Table 1). At the hospital level, a high volume of admissions for acute cholecystitis was associated with increased odds of early cholecystectomy (Table 1). Albeit significant, the level of operating room use after hours showed an inconsistent association with the performance of early cholecystectomy. The model showed good discrimination $(c$-statistic $=0.80)$ and calibration. The univariable analysis results are available in Appendix 1 .

We then used the multilevel model to quantify the extent of variation between hospitals, adjusted for differences in patient case-mix. The median OR was 3.7 , which can be interpreted as a nearly 4-fold median difference in the odds of

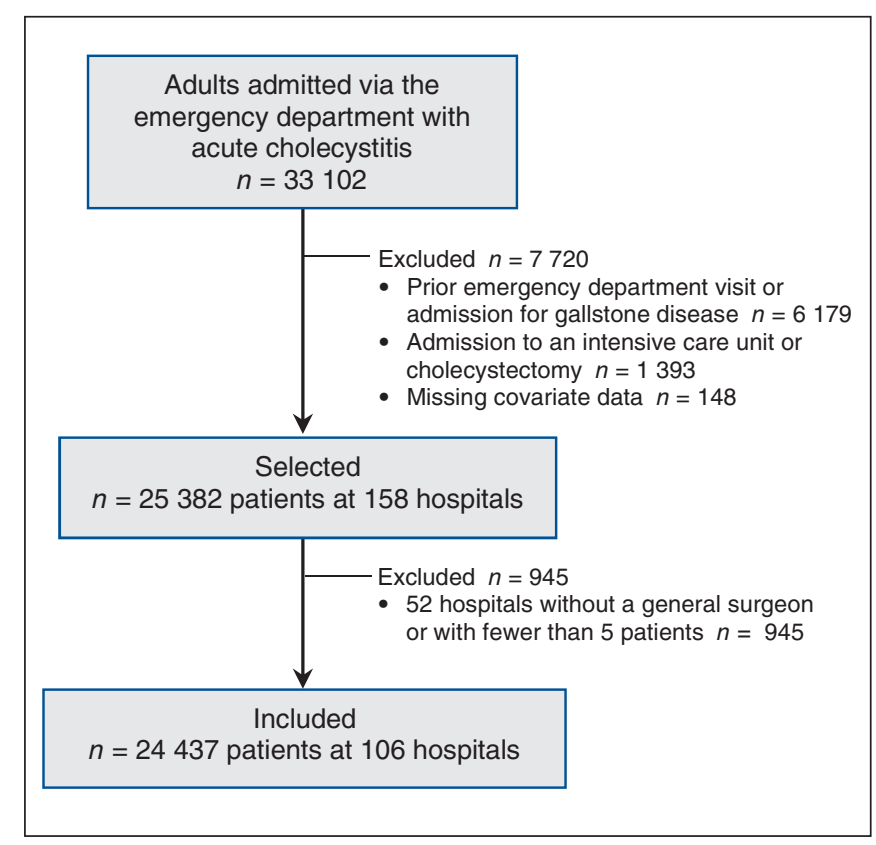

Figure 1: Selection of patients and hospitals. 
early cholecystectomy for 2 similar patients admitted to randomly selected hospitals.

Finally, we examined the explained outcome variation attributable to patient and hospital characteristics. Our multilevel model explained $53 \%$ of the variation in the frequency of early cholecystectomy. Of this explained variation, about half (27\%) could be attributed to hospital characteristics and half (26\%) to patient characteristics.

\section{Interpretation}

In this population-based study evaluating the practice of early cholecystectomy for acute cholecystitis, we found significant variation across hospitals, even when we considered only young healthy patients with uncomplicated disease. Our analysis suggests that 2 similar patients who present to randomly selected hospitals have an almost 4-fold median difference in their respective odds of early cholecystectomy. Furthermore, hospital effects, as opposed to patient effects, accounted for half of the explained variation in early cholecystectomy rates. Admission to a hospital with a high admission

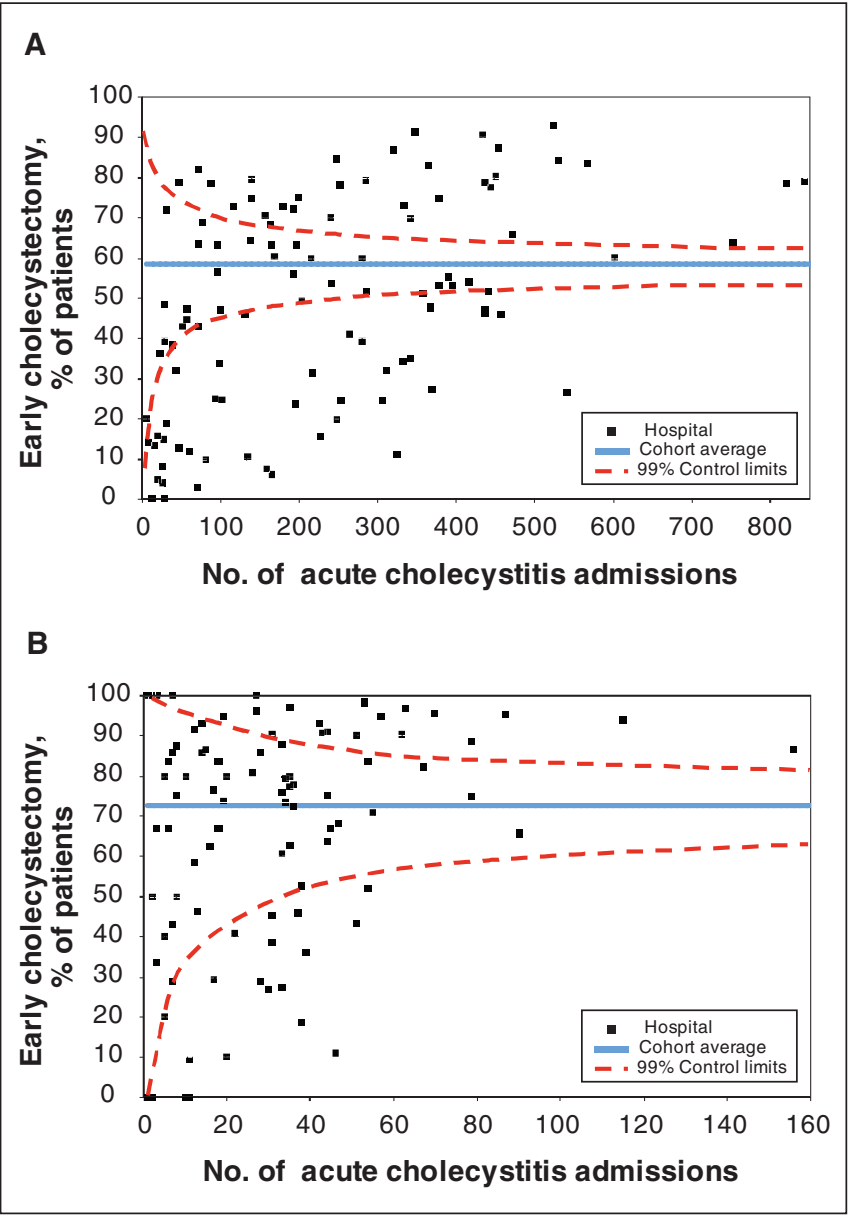

Figure 2: Rate of early cholecystectomy across hospitals among (A) all included patients ( $n=24437$ at 106 hospitals) and (B) young healthy patients $(<50 \mathrm{yr}$, in the lowest comorbidity quartile and with uncomplicated disease [without concurrent biliary tract obstruction or pancreatitis]; $n=2894$ at 102 hospitals). volume of patients with acute cholecystitis was associated with the highest rate of early intervention.

Best available evidence supports early (v. delayed) laparoscopic

Table 1: Multilevel multivariable logistic regression of the association between patient and hospital characteristics and undergoing early cholecystectomy (within $7 \mathrm{~d}$ of presentation to an emergency department)

\begin{tabular}{|c|c|}
\hline Characteristic & $\begin{array}{l}\text { Adjusted OR } \\
(99 \% \mathrm{Cl})^{\star}\end{array}$ \\
\hline \multicolumn{2}{|l|}{ Patient } \\
\hline \multicolumn{2}{|l|}{ Age, yr } \\
\hline $18-35$ & Ref \\
\hline $36-50$ & $0.92(0.81-1.05)$ \\
\hline $51-65$ & $0.69(0.61-0.79)$ \\
\hline $66-80$ & $0.46(0.40-0.53)$ \\
\hline$>80$ & $0.21(0.18-0.25)$ \\
\hline Male sex & $0.87(0.80-0.95)$ \\
\hline \multicolumn{2}{|l|}{ Income quintile } \\
\hline 1 (lowest) & Ref \\
\hline 2 & $0.98(0.87-1.10)$ \\
\hline 3 & $0.93(0.82-1.05)$ \\
\hline 4 & $1.06(0.94-1.21)$ \\
\hline 5 & $1.12(0.98-1.27)$ \\
\hline \multicolumn{2}{|l|}{ Comorbidity index quartile } \\
\hline 1 (lowest) & Ref \\
\hline 2 & $0.90(0.80-1.01)$ \\
\hline 3 & $0.89(0.79-1.00)$ \\
\hline 4 & $0.67(0.60-0.75)$ \\
\hline Common bile duct obstruction & $0.41(0.36-0.47)$ \\
\hline Pancreatitis & $1.14(0.94-1.37)$ \\
\hline \multicolumn{2}{|l|}{ Hospital } \\
\hline \multicolumn{2}{|c|}{ Annual volume of acute cholecystitis admissions (quartile) } \\
\hline $5-17$ & $0.53(0.35-0.78)$ \\
\hline 18-39 & $0.67(0.52-0.87)$ \\
\hline $40-65$ & $0.84(0.72-0.97)$ \\
\hline $66-164$ & Ref \\
\hline \multicolumn{2}{|c|}{ After-hours operating room use† (quartile) } \\
\hline 1 (lowest) & $0.97(0.72-1.30)$ \\
\hline 2 & $0.84(0.66-1.07)$ \\
\hline 3 & $0.79(0.64-0.97)$ \\
\hline 4 & Ref \\
\hline \multicolumn{2}{|c|}{ Annual volume of elective cholecystectomies (quartile) } \\
\hline $0-74$ & $1.02(0.63-1.63)$ \\
\hline $75-159$ & $1.15(0.82-1.60)$ \\
\hline $160-279$ & $1.11(0.91-1.35)$ \\
\hline 280-905 & Ref \\
\hline Academic teaching hospital & $0.71(0.27-1.85)$ \\
\hline \multicolumn{2}{|c|}{$\begin{array}{l}\text { Note: } \mathrm{Cl}=\text { confidence interval, } \mathrm{OR}=\text { odds ratio, Ref }=\text { reference. } \\
\text { *All listed covariates were included in a multivariable model that also accounted } \\
\text { for the nonindependence of patients admitted to the same hospital. } \\
\text { † Ratio of total after-hours operative cases (for all surgical specialties) divided by } \\
\text { the number of all-cause emergency department visits. }\end{array}$} \\
\hline
\end{tabular}


cholecystectomy for most patients with acute cholecystitis; this is based on findings of a shortened total hospital stay, a similar conversion rate to open cholecystectomy and the elimination of the risk of recurrent gallstone symptoms associated with delayed elective cholecystectomy., ${ }^{3,8-13}$ Although these findings come from randomized trials published between 1998 and $2005,^{8-12}$ inconsistency in the practice of early cholecystectomy remains evident across different practice environments internationally, with reported rates of early cholecystectomy ranging from $36 \%$ to $88 \% .{ }^{14-18}$ Previous studies have also shown that, among patients aged 66 years and older, early cholecystectomy is less likely in patients of greater age and comorbidity level and that early cholecystectomy is less likely with limited insurance status in the United States. ${ }^{17,18}$ Other determinants of management identified in surveys of physicians include surgeons' competing elective clinical obligations, surgeons' comfort with laparoscopy and the availability of hospital resources for emergency surgery. ${ }^{33-35}$ Although we found patient characteristics associated with management that are consistent with the literature, our study also describes the wide extent of variation across hospitals within a large regional health care system and quantified the importance of hospitallevel effects as a source of variation in practice.

Most patients in the cohort received early cholecystectomy; however, we have shown that similar patients at different hospitals across Ontario did not receive comparable care. We postulate that these results may, in part, be related to logistic barriers to early cholecystectomy at certain institutions. Variation across hospitals in the management of acute cholecystitis may be reduced in the future because of a recent focus on the efficient delivery of emergency surgical care. This focus includes the American College of Surgeons' support for the emerging field of acute care surgery, as well as the Royal College of Surgeons of England's promotion of the separation of emergency and elective surgical practice. ${ }^{36,37}$ Initiatives targeting better delivery of emergency surgical care (e.g., including a dedicated service for emergency surgery referrals, a surgeon-of-the-week practice model and operating room time during the day dedicated to emergency cases) are likely to facilitate early cholecystectomy. Recent evidence supports a dedicated emergency surgery team as the catalyst for more efficient management of gallstone disease. ${ }^{38-42}$ In addition, variation in practice may in part reflect the need to address remaining gaps in the evidence comparing the outcomes of early and delayed cholecystectomy. One of the factors hindering the uptake of early cholecystectomy may be concern that early intervention is associated with a higher rate of major bile duct injury, ${ }^{6}$ a rare but devastating operative complication. Adequately powered studies assessing whether this is true, as well as a comparison of real-world rates of conversion from laparoscopic to open cholecystectomy, are required.

\section{Strengths and limitations}

The main strengths of this study include its population-based scope, the quality of the data sources, and the study setting a health care system in which emergency surgical care is only accessed through single-payer-funded public hospitals.
Our study also has limitations. The first is potential residual confounding related to the severity of cholecystitis. We attempted to reduce this potential bias by excluding patients with severe cholecystitis and prior gallstone disease. Although there is likely a gradient of severity (captured by duration of symptoms, leukocyte count, gallbladder wall thickness on ultrasound) present in our study cohort, it is reasonable to expect that this gradient would be similarly distributed across hospitals, particularly after adjustment for age, sex, socioeconomic status and comorbidity level. Furthermore, we believe that the extent of variation across hospitals is too large to be fully explained by unmeasured differences in cholecystitis severity.

The second limitation is that we are unable to identify the decision-making surgeon from our data sources. Nevertheless, many surgeon characteristics, such as practice type and cholecystectomy volume, would be expected to overlap with the hospital characteristics we included. As such, the measured hospital effects are likely partly attributable to the hospitals' surgeons, and characterizing the relative importance of surgeon-level variation in practice merits further investigation. Despite this limitation, understanding variation at the hospital level remains a constructive starting point to generate solutions for quality improvement.

Finally, definitions of the time frame for early cholecystectomy range in the literature between 24 hours and 7 days from symptom onset or diagnosis.6 Although we chose a broad time frame (within $7 \mathrm{~d}$ from emergency department presentation), when we defined early cholecystectomy as occurring within 3 days of presentation to an emergency department, we found the same extent of variation and similar associations on multivariable analysis (data available on request).

\section{Conclusion}

We found that similar patients with acute cholecystitis did not receive comparable care across the hospitals of a large regional health care system. Hospital-level factors, independent of patient characteristics, were found to be strongly related to practice variation. Hospital-specific initiatives should be considered to facilitate early cholecystectomy for acute cholecystitis.

\section{References}

1. Russo MW, Wei JT, Thiny MT, et al. Digestive and liver diseases statistics, 2004. Gastroenterology 2004;126:1448-53.

2. Williams JG, Roberts SE, Ali MF, et al. Gastroenterology services in the UK. The burden of disease, and the organisation and delivery of services for gastrointestinal and liver disorders: a review of the evidence. Gut 2007;56(Suppl 1):1-113.

3. Gurusamy K, Samraj K, Gluud C, et al. Meta-analysis of randomized controlled trials on the safety and effectiveness of early versus delayed laparoscopic cholecystectomy for acute cholecystitis. Br F Surg 2010;97:141-50.

4. Yamashita Y, Takada T, Strasberg SM, et al. TG13 surgical management of acute cholecystitis. 7 Hepatobiliary Pancreat Sci 2013;20:89-96.

5. Guidelines for the clinical application of laparoscopic biliary tract surgery. Los Angeles (CA): Society of American Gastrointestinal and Endoscopic Surgeons; 2010. Available: www.sages.org/publication/id/06/ (accessed 2013 Jan.).

6. Strasberg SM. Clinical practice. Acute calculous cholecystitis. $N$ Engl 7 Med 2008;358:2804-11.

7. Germanos S, Gourgiotis S, Kocher HM. Clinical update: early surgery for acute cholecystitis. Lancet 2007;369:1774-6.

8. Lai PB, Kwong KH, Leung KL, et al. Randomized trial of early versus delayed laparoscopic cholecystectomy for acute cholecystitis. Br 7 Surg 1998; $85: 764-7$. 
9. Lo CM, Liu CL, Fan ST, et al. Prospective randomized study of early versus delayed laparoscopic cholecystectomy for acute cholecystitis. Ann Surg 1998; 227:461-7.

10. Kolla SB, Aggarwal S, Kumar A, et al. Early versus delayed laparoscopic cholecystectomy for acute cholecystitis: a prospective randomized trial. Surg Endosc 2004; 18:1323-7.

11. Johansson M, Thune A, Blomqvist A, et al. Management of acute cholecystitis in the laparoscopic era: results of a prospective, randomized clinical trial. $\mathcal{f}$ Gastrointest Surg 2003;7:642-5.

12. Davila D, Manzanares C, Picho ML, et al. Experience in the treatment (early vs. delayed) of acute cholecystitis via laparoscopy. Cir Esp 1999;66(Suppl 1):233.

13. de Mestral C, Rotstein OD, Laupacis A, et al. A population-based analysis of the clinical course of 10,304 patients with acute cholecystitis, discharged without cholecystectomy. 7 Trauma Acute Care Surg 2013;74:26-30.

14. Stephens MR, Beaton C, Steger AC. Early cholecystectomy after acute admission with cholecystitis: How much work? World 7 Surg 2010;34:2041-4.

15. Lee SW, Yang SS, Chang CS, et al. Impact of the Tokyo guidelines on the management of patients with acute calculous cholecystitis. 7 Gastroenterol Hepatol 2009;24:1857-61.

16. Casillas RA, Yegiyants S, Collins JC. Early laparoscopic cholecystectomy is the preferred management of acute cholecystitis. Arch Surg 2008;143:533-7.

17. Riall TS, Zhang D, Townsend CM, et al. Failure to perform cholecystectomy for acute cholecystitis in elderly patients is associated with increased morbidity, mortality, and cost. 7 Am Coll Surg 2010;210:668-77.

18. Greenstein AJ, Moskowitz A, Gelijns AC, et al. Payer status and treatment paradigm for acute cholecystitis. Arch Surg 2012;147:453-8.

19. Juurlink D, Preyra C, Croxford R, et al. Canadian Institute for Health Information Discharge Abstract Database: a validation study. Toronto (ON): Institute for Clinical Evaluative Sciences; 2006.

20. Austin PC, Daly PA, Tu JV. A multicenter study of the coding accuracy of hospital discharge administrative data for patients admitted to cardiac care units in Ontario. Am Heart 7 2002; 144:290-6.

21. Gershon AS, Wang C, Guan J, et al. Identifying individuals with physician diagnosed COPD in health administrative databases. COPD 2009;6:388-94.

22. Hux JE, Ivis F, Flintoft V, et al. Diabetes in Ontario: determination of prevalence and incidence using a validated administrative data algorithm. Diabetes Care 2002;25:512-6.

23. Tu K, Chen Z, Lipscombe LL. Canadian Hypertension Education Program Outcomes Research Taskforce. Prevalence and incidence of hypertension from 1995 to 2005: a population-based study. CMA7 2008;178:1429-35.

24. Hirota M, Takada T, Kawarada Y, et al. Diagnostic criteria and severity assessment of acute cholecystitis: Tokyo guidelines. 7 Hepatobiliary Pancreat Surg 2007;14:78-82.

25. Glazier RH, Creatore MI, Agha MM, et al. Inner City Toronto Time Trends Working Group. Socioeconomic misclassification in Ontario's Health Care Registry. Can 7 Public Health 2003;94:140-3.

26. Johns Hopkins ACG case-mix adjustment system. Baltimore (MD): Johns Hopkins University. Available: www.acg.jhsph.edu (accessed 2012 July 1).

27. Austin PC, Walraven C. The mortality risk score and the ADG score: two points-based scoring systems for the Johns Hopkins aggregated diagnosis groups to predict mortality in a general adult population cohort in Ontario, Canada. Med Care 2011;49:940-7.

28. Classification of hospitals. Ottawa (ON): Ontario Ministry of Health and Long Term Care; 2009. Available: www.health.gov.on.ca/english/public/contact/hosp /group_a.html (accessed 2012 July 1).

29. Spiegelhalter DJ. Funnel plots for comparing institutional performance. Stat Med 2005;24:1185-202.

30. Austin PC, Tu JV, Alter DA. Comparing hierarchical modeling with traditional logistic regression analysis among patients hospitalized with acute myocardial infarction: Should we be analyzing cardiovascular outcomes data differently? Am Heart 7 2003;145:27-35.

31. Mittlböck M, Schemper M. Explained variation for logistic regression. Stat Med 1996;15:1987-97.

32. Larsen K, Merlo J. Appropriate assessment of neighborhood effects on individ- ual health: integrating random and fixed effects in multilevel logistic regression. Am 7 Epidemiol 2005;161:81-8.

33. Campbell EJ, Montgomery DA, Mackay CJ. A national survey of current surgical treatment of acute gallstone disease. Surg Laparosc Endosc Percutan Tech 2008; 18:242-7.

34. Yamashita Y, Takada T, Hirata K. A survey of the timing and approach to the surgical management of patients with acute cholecystitis in Japanese hospitals. 7 Hepatobiliary Pancreat Surg 2006;13:409-15.

35. Cameron IC, Chadwick C, Phillips J, et al. Management of acute cholecystitis in UK hospitals: time for a change. Postgrad Med 7 2004;80:292-4.

36. Hoyt DB. Looking forward. Bull Am Coll Surg 2011;96:5-6.

37. Separating emergency and elective surgical care: recommendations for practice. London (UK): Royal College of Surgeons of England; 2007. Available: www.rcseng .ac.uk/publications/docs/separating_emergency_and_elective.html?searchterm =separating (accessed 2012 July 1).

38. Lau B, Difronzo LA. An acute care surgery model improves timeliness of care and reduces hospital stay for patients with acute cholecystitis. Am Surg 2011; 77:1318-21.

39. Agrawal S, Battula N, Barraclough L, et al. Early laparoscopic cholecystectomy service provision is feasible and safe in the current UK National Health Service. Ann R Coll Surg Engl 2009;91:660-4.

40. Simpson DJ, Wood AM, Paterson HM, et al. Improved management of acute gallstone disease after regional surgical subspecialization. World 7 Surg 2008;32: 2690-4.

41. Lehane CW, Jootun RN, Bennett M, et al. Does an acute care surgical model improve the management and outcome of acute cholecystitis? ANZ 7 Surg 2010;80:438-42.

42. Britt RC, Bouchard C, Weireter LJ, et al. Impact of acute care surgery on biliary disease. 7 Am Coll Surg 2010;210:595-9.

Affiliations: From the Sunnybrook Research Institute (de Mestral, Haas, Gomez, Nathens), Sunnybrook Health Sciences Centre and the Li Ka Shing Knowledge Institute (Laupacis, Rotstein, Hoch, Nathens), St. Michael's Hospital, University of Toronto; and the Institute for Clinical Evaluative Sciences (de Mestral, Laupacis, Hoch, Zagorski, Nathens), Toronto, Ont.

Contributors: All authors contributed to study design. Charles de Mestral and Brandon Zagorski created the cohort. Charles de Mestral, Barbara Haas, David Gomez, Brandon Zagorski and Avery Nathens contributed to the statistical analysis. All authors interpreted the results. Charles de Mestral drafted the manuscript. All authors were responsible for critical revisions and approved the final version submitted for publication.

Funding: This study was funded by operating grants from the Canadian Surgical Research Fund and Physician Services Inc. Foundation. This study was also supported by the Institute for Clinical Evaluative Sciences (ICES), which is funded by an annual grant from the Ontario Ministry of Health and Long-Term Care (MOHLTC). The opinions, results and conclusions reported in this paper are those of the authors and are independent from the funding sources. No endorsement by ICES or the Ontario MOHLTC is intended or should be inferred.

Acknowledgements: Charles de Mestral and Avery Nathens have received a Canadian Surgical Research Fund Operating grant and Physician Services Inc. Foundation Operating grant. Charles de Mestral is also a recipient of an Ontario Doctoral Award.

Supplemental information: For reviewer comments and the original submission of this manuscript, please see www.cmajopen.ca/content/1/2 /E62/suppl/DC1. 